\title{
Influência de métodos silviculturais para o controle de plantas infestantes sobre o crescimento de mudas de Eucalyptus L'Hér., 1789
}

\author{
Influence of the silvicultural methods of weed control \\ on the growth of Eucalyptus L'Hér., 1789
}

Pablo Georgio de Souza ${ }^{[a]}$, Nilton José Sousa ${ }^{[b]}$, Daniele Ukan ${ }^{[c]}$

[a] Engenheiro florestal, Mestre, Doutorando pela Universidade Federal do Paraná (UFPR), professor da Pontifícia Universidade Católica do Paraná (PUCPR), São José dos Pinhais, PR - Brasil, e-mail: pablo.souza@pucpr.br

[b] Engenheiro florestal, Doutor, professor da Universidade Federal do Paraná (UFPR), Curitiba, PR - Brasil, e-mail: nilton.ufpr@gmail.com

[c] Engenheira florestal, Mestre, Doutoranda pela Universidade Federal do Paraná (UFPR), professora da Unicentro, Irati, PR - Brasil, e-mail: daniukan@yahoo.com.br

\section{Resumo}

Medidas adotadas para o controle das plantas infestantes em áreas de cultivo florestal são alvos de muitos questionamentos, referentes à sua real necessidade, sobre qual a técnica ideal, qual o melhor custo benefício, se seu efeito é realmente significativo. Com o objetivo geral de avaliar a influência do uso do controle químico e da aplicação de roçadas semimecanizadas sobre o crescimento diamétrico de mudas de Eucalyptus L'Hér., 1789 e mortalidade, experimentos foram implantados no município de Joinville, SC, onde foi avaliado o crescimento diamétrico das mudas de eucaliptos, submetidas ao efeito de diferentes métodos de controle de plantas infestantes na linha de plantio (coroa), entrelinhas e em área total, com a utilização de tratamentos de controle semimecanizado, controle químico e testemunhas. Este experimento possibilitou concluir que: o crescimento diamétrico das mudas é favorecido pelo controle semimecanizado de plantas infestantes em área total; as mudas submetidas aos tratamentos com herbicida glyphosate apresentam um crescimento final inferior ao das mudas submetidas aos tratamentos com roçadas; problemas operacionais durante a aplicação das técnicas de controle químico influenciam significativamente o crescimento das variáveis diâmetro do colo nas unidades amostrais submetidas a essa técnica.

Palavras-chave: Plantas infestantes. Silvicultura. Eucalyptus L’Hér., 1789.

\section{Abstract}

Measures taken to control the weeds in cultivated forest areas are targets of many questions, concerning its real need, about what technique is ideal, what is the most cost-effective and if its effect is really significant. With the objective of evaluating the influence of the use of chemical control and application of semi-mechanized 
mowing on the diameter growth of Eucalyptus L'Her., 1789, and mortality, experiments were conduted in the area of Joinville - SC, where is was evaluated the diameter growth of eucalyptus seedlings, subjected to the effect of different methods of weed control in row (crown), and between lines in the total area, using semimechanized, are chemical treatments, and a control. This experiment allowed to conclude that: the diameter growth of seedlings is favored by the semi-mechanical control of weeds in total area; the seedlings subjected to treatment with the herbicide glyphosate have a lower limit to the growth of seedlings to treated with mowing; operational problems during the application of chemical control techniques significantly influenced the growth of the variable diameter, in the sample units submitted to this technique.

Keywords: Oportunistic plants. Silviculture. Eucalyptus L'Hér., 1789.

\section{Introdução}

Entre as atividades que são consideradas imprescindíveis para o sucesso da implantação de um plantio de Eucalyptus L'Hér., 1789, as manutenções para o controle de plantas infestantes ocupam posição de destaque, pois, segundo Toledo (1998), podem totalizar mais de $60 \%$ do custo de implantação dessa cultura.

0 problema das plantas infestantes é tão antigo quanto a própria agricultura. A sua origem é atribuída ao próprio homem, que no afã de melhorar as espécies úteis retirou-lhes gradativamente a agressividade. A natureza, por sua vez, agiu sobre as plantas silvestres no sentido contrário, ou seja, imprimindo-lhes uma seleção no sentido de torná-las cada vez mais eficientes quanto à sobrevivência (LORENZI, 2000).

Entende-se por formação de uma floresta implantada o período compreendido entre o plantio da muda no local definitivo até o momento em que esta passa a dominar a vegetação espontânea do local (FERREIRA, 1977). Christoffoleti et al. (1998), com base nessa definição, deixam claro que qualquer medida de manejo das plantas infestantes, com o objetivo de favorecer o desenvolvimento das plantas florestais, é importante para o sucesso da implantação de culturas florestais.

Segundo Kreijci e Lourenço (1987), ao se pensar em um programa de controle das plantas infestantes em reflorestamento, é importante saber em que época elas representam o maior grau de competição com a cultura e determinar o método mais apropriado para a execução do controle. 0 controle tardio, após a competição já estabelecida, implica o aumento do percentual de falhas e de árvores dominadas, o que afeta significativamente a produtividade final das florestas.
A presença de plantas infestantes no ecossistema florestal condiciona a ação (ou provoca mudança na intensidade de atuação) de inúmeros fatores ecológicos, alguns favoráveis e outros desfavoráveis ao interesse das empresas florestais (ALVES, 1992).

A interferência de plantas infestantes tem sido o grande problema na implantação e manutenção de florestas de Eucalyptus L'Hér., 1789 e Pinus spp., o que pode ser confirmado por alguns estudos, os quais demonstram que essas plantas causam prejuízos ao crescimento e à produtividade. À medida que essas plantas competem por luz, nutrientes, água e "nicho ecológico", exercem pressão de natureza alelopática, aumentam riscos de incêndios e outros, justificando plenamente a preocupação com seu controle (PITELLI, 1987; PITELLI; MARCHI, 1991). Além desses fatores, também devem ser considerados os custos progressivos de mão de obra necessária para as operações de limpeza e manutenção desses plantios (TOLEDO et al., 1996).

Dentre as interferências diretas sobre as espécies florestais destacam-se: a interferência competitiva, que é a redução de um ou mais recursos limitantes, como a água, os nutrientes e a interceptação de luz; e a interferência alelopática, que é a produção e a liberação de compostos químicos por tecidos vivos ou em decomposição, que interferem no crescimento de plantas próximas (TOLEDO, 1998).

A comunidade de plantas infestantes pode interferir diretamente, depreciando a qualidade do produto florestal. Por exemplo, algumas plantas infestantes - trepadeiras ou cipós - enrolam-se junto ao tronco das espécies florestais, impedindo o seu crescimento e forçando o aparecimento de brotações laterais, ocasionando nós (TOLEDO, 1998).

A interceptação da luz solar é uma das modalidades de interferência das plantas infestantes que 
provoca maior impacto sobre o crescimento das espécies florestais, pois restringe a fonte predominante de energia aos processos básicos de recrutamento dos elementos e de todas as substâncias envolvidas no crescimento e desenvolvimento do vegetal (PITELLI; MARCHI, 1991).

Segundo Cobucci, Di Stefano e Kluthcouski (1999), o manejo de plantas infestantes envolve atividades dirigidas (manejo direto) e/ou o sistema formado pelo solo e pela cultura (manejo indireto). 0 manejo direto refere-se à eliminação direta das plantas infestantes com uso de herbicidas, ação mecânica ou manual e ação biológica. No manejo do solo (manejo indireto) se trabalha com a relação sementes ativas e inativas. Esse manejo, se realizado de forma correta, de acordo com Primavesi (2002), pode reduzir os custos em até $30 \%$.

Para Cobucci, Di Stefano e Kluthcouski (1999), a estratégia de controle das plantas infestantes deve associar o melhor método e o momento oportuno, antes do período crítico de competição. A escolha do método, entretanto, deve estar relacionada às condições locais de mão de obra e de implementos, sempre considerando a análise de custos. Deve-se utilizar a associação de métodos sempre que possível.

As técnicas de controle de plantas infestantes são classificadas em controle: cultural, químico, físico, mecânico, biológico, legislativo, dentre os quais o objetivo principal é manter a comunidade infestante abaixo dos níveis de significância econômica (WIKLER, 2000).

0 controle químico é constituído pelo uso de substâncias com ação herbicida, capazes de controlar e/ou interromper o crescimento das plantas indesejadas, de forma seletiva ou não, favorecendo o desenvolvimento da cultura de interesse ou plantas econômicas (DEUBER, 1997).

0 uso de herbicidas é uma das alternativas para o controle da vegetação daninha em complementação ao método mecânico. A utilização do herbicida glyphosate no controle de plantas infestantes em cultivos florestais tem crescido rapidamente nos últimos anos. Esse fato tem ocorrido por uma série de razões, incluindo a grande eficiência do produto em uma série de plantas infestantes de habitat florestal (CHRISTOFFOLETI, 1998).

Glyphosate, N-(phosphonomethyl) glycine, é uma molécula sistêmica e não seletiva usada para controlar espécies de folhas largas, gramíneas e ciperáceas. Muitos herbicidas à base de glyphosate utilizam o sal isopropylamine de glyphosate (RODRIGUES; ALMEIDA, 2005).

Segundo o Environmental Protection Agency (EPA), o modo de ação do glyphosate ainda não é bem conhecido (COX, 1998). Já o controle mecânico consiste em promover o arranquio ou o corte das plantas infestantes, em geral, com algum tipo de equipamento (FONTES et al. 2003), e o método semimecanizado consiste na utilização de roçadeira costal ou motocultivador. Contudo, esses métodos não controlam efetivamente as invasoras, que também rebrotam com vigor, porém, podendo ser implementadas de forma seletiva, cortando apenas a vegetação infestante (EMBRAPA, 2008).

0 presente trabalho objetiva avaliar quantitativamente e qualitativamente a influência de diferentes direcionamentos de roçadas e aplicação de herbicidas sobre o crescimento diamétrico de mudas de Eucalyptus L'Hér., 1789, e o percentual de mortalidade.

\section{Materiais e métodos}

Os experimentos aqui descritos foram realizados entre os meses de fevereiro e dezembro de 2007, no Projeto Purunã, localizado no município de Joinville, SC (Figura 1), de propriedade da empresa Comfloresta, com latitude Sul de $26^{\circ} 33^{\prime} 97^{\prime \prime}$ e $48^{\circ} 74^{\prime} 10^{\prime \prime}$ de longitude Oeste.

0 relevo do local é plano, o solo predominante é do tipo neossolo quartzarênico, segundo o sistema nacional de classificação de solos da Embrapa (1999). A região possui clima do tipo Cfa (clima temperado úmido com verão quente), segundo a classificação de Köppen. A vegetação é, segundo a classificação de 1992 do Instituto Brasileiro de Geografia e Estatística (IBGE), do tipo Floresta Ombrófila Densa Submontana, a qual se caracteriza por sua ocorrência em áreas de clima tropical quente e úmido, sem período biologicamente seco, com chuvas bem distribuídas durante o ano (excepcionalmente com períodos de até 60 dias de umidade escassa) e temperaturas médias variando entre $22^{\circ} \mathrm{C}$ a $25^{\circ} \mathrm{C}$.

\section{Preparação da área}

0 preparo inicial do terreno foi aplicado, de forma padronizada, em área total, com a utilização dos 


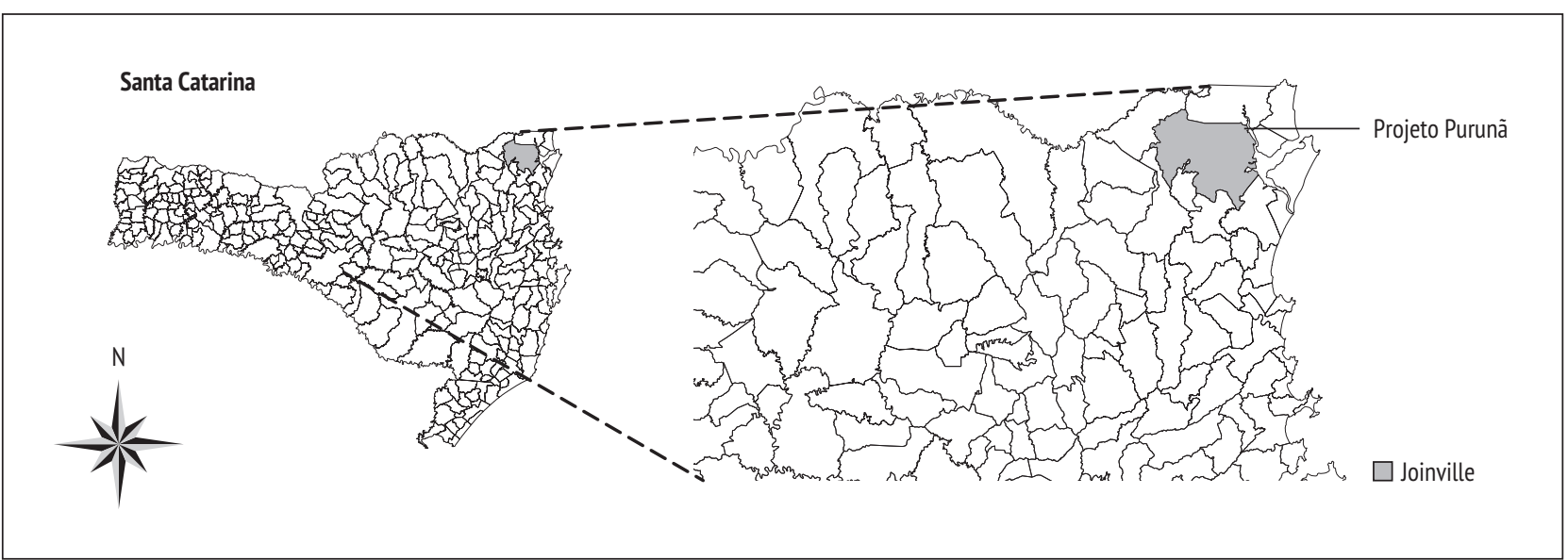

Figura 1 - Localização geográfica do Projeto Purunã

mesmos equipamentos e os mesmos procedimentos de preparo, seguindo a seguinte sequência operacional: limpeza inicial do terreno de forma mecanizada com a utilização de trator de esteira (60 dias antes do plantio); enleiramento dos resíduos com a utilização de trator de esteira (40 a 50 dias antes do plantio); subsolagem do terreno com a utilização de um trator traçado e implemento escarificador do tipo "Ripper" com uma haste e dois discos para a formação de camaleão (operação realizada na sequência do enleiramento).

Após o preparo do terreno foi realizada, em toda a área do experimento, a aplicação de herbicida pósemergente, ingrediente ativo glyphosate (produto comercial NA wg, concentração de 79,25\%, classe toxicológica IV, classificação ambiental III $^{1}$ ), com a utilização de 3 quilogramas do produto comercial, sendo 2,3775 quilogramas do ingrediente ativo glyphosate por hectare. A calda foi preparada com o produto e o solvente (água), sem a adição de outros produtos; ao todo foram utilizados 300 litros de calda por hectare. A aplicação foi realizada com a utilização de um trator de pneus agrícolas traçado e um tanque de pulverização com capacidade para 600 litros.

0 controle de formigas cortadeiras foi realizado com a utilização de "microporta-iscas - MIPI de 5 gramas", contendo iscas com ingrediente ativo sulfluramida, (produto comercial, concentração 0,3\%, classe toxicológica IV, classificação ambiental III), dez dias antes da realização do plantio, e o repasse foi realizado simultaneamente ao plantio das mudas.
0 plantio das mudas de Eucalyptus L'Hér., 1789, foi realizado de forma semimecanizada (com a utilização de plantadeiras manuais), 15 dias após a aplicação do herbicida, com espaçamento de 2 metros entre plantas e 3 metros entrelinhas de plantio. 0 replantio foi realizado 10 dias após o plantio, simultaneamente à alocação das parcelas para a realização do experimento.

As plantas foram adubadas em duas ocasiões com doses de 100 gramas de adubo químico (formulação NPK 10-20-15 mais micronutrientes) em cada adubação, sendo a primeira aplicação realizada 25 dias após o plantio das mudas e a segunda, 55 dias após o plantio (aplicações realizadas com a utilização de adubadeiras manuais).

\section{Tratamentos}

Os tratamentos relatados abaixo visaram a possibilitar a avaliação da influência das distintas técnicas de controle de plantas infestantes sobre o crescimento de mudas de Eucalyptus L'Hér., 1789. Para tanto, convencionou-se que os tratamentos deste trabalho teriam diferentes direcionamentos na utilização de um herbicida pós-emergente, com ingrediente ativo glyphosate, e de roçadas semimecanizadas, com a utilização de roçadeira costal (Tabela 1).

Tratamento 1 (T1): controle das plantas infestantes em área total, com o uso de roçadeira costal (roçada semimecanizada) com intervalos regulares de 30 dias a partir da implantação do experimento,

\footnotetext{
1 Disponível em: <http://agrofit.agricultura.gov.br>.
} 
totalizando 10 intervenções durante o período de avaliações com o objetivo de manter as parcelas desse tratamento limpas permanentemente.

Tratamento 2 (T2): testemunha, onde não foram realizadas atividades de controle das plantas infestantes após implantação da cultura, buscando manter as condições naturais de competição e concorrência entre as plantas infestantes e a cultura de interesse.

Tratamento 3 (T3): controle das plantas infestantes em área total, com o uso de roçadeira costal (roçada semimecanizada) em duas ocasiões, sendo a primeira aos 75 dias após a avaliação inicial e a segunda realizada aos 75 dias após a primeira.

Tratamento 4 (T4): controle das plantas infestantes nas "entrelinhas" de plantio, com o uso de roçadeira costal (roçada semimecanizada) com as intervenções repetidas duas vezes, sendo a primeira roçada realizada 75 dias após a avaliação inicial e a segunda, 150 dias após a avaliação inicial.

Tratamento 5 (T5): controle das plantas infestantes nas coroas das plantas da cultura de eucaliptos, com um raio médio de 1 metro em torno de cada planta, sendo executada com o uso de roçadeira costal (roçada semimecanizada). Assim como nos tratamentos T3 e T4, esse tratamento foi executado em duas ocasiões: a primeira 75 dias após a implantação do experimento e a segunda 150 dias após a implantação das unidades amostrais.

Tratamento 6 (T6): controle das plantas infestantes em área total, com a utilização de herbicida, ingrediente ativo glyphosate, com aplicações realizadas em duas vezes com intervalos de 75 dias, sendo a primeira 75 dias e a segunda 150 dias após a avaliação inicial. A calda de glyphosate NA wg foi preparada com o produto comercial e água, sendo utilizados 200 gramas do herbicida comercial para cada 16 litros de água e, em cada parcela desse tratamento, foi aplicada uma quantidade correspondente a 12 litros de calda por intervenção, correspondente a 300 litros de calda por hectare por manutenção $(3,75 \mathrm{~kg}$ de ingrediente ativo $/ \mathrm{ha} * 2=7,5 \mathrm{~kg}$ de ingrediente ativo).

Tratamento 7 (T7): controle das plantas infestantes nas "entrelinhas" de plantio, com a utilização de herbicida, ingrediente ativo glyphosate, aplicado com as mesmas técnicas já citadas, doses e intervalos de tempo que o tratamento 6 , sendo calda preparada com o produto comercial NA wg e água, utilizando 200 gramas do herbicida para cada 16 litros de água, no qual foi aplicada uma quantidade correspondente a 6 litros de calda por unidade amostral, equivalente a 150 litros por hectare $(1,875 \mathrm{~kg} / \mathrm{ha} * 2=$ $3,75 \mathrm{~kg}$ de ingrediente ativo).

Tratamento 8 (T8): controle das plantas infestantes nas coroas das plantas da cultura de interesse, com a utilização de herbicida, ingrediente ativo glyphosate, aplicado com as mesmas técnicas já citadas, com as doses e as intervenções repetidas duas vezes, sendo a primeira roçada realizada 75 dias após a avaliação inicial e a segunda, 150 dias após. Assim como nos tratamentos T6 e T7, a calda foi preparada com o produto comercial NA wg e água, sendo utilizados 200 gramas do herbicida para cada 16 litros de água e, em cada parcela aplicada, uma quantidade correspondente a 4,5 litros de calda, o equivalente a 112,5 litros por hectare $(1,406 \mathrm{~kg} / \mathrm{ha}$ $* 2=2,812 \mathrm{~kg}$ de ingrediente ativo).

Tabela 1 - Tratamentos de controle de plantas infestantes

\begin{tabular}{llll}
\hline Tratamentos & Técnica de limpeza utilizada & Equipamento & Período de aplicação \\
\hline T1 & Roçada em área total & Roçadeira costal & A cada 30 dias após a $1^{\text {a }}$ avaliação \\
T2 & Testemunha sem limpeza & - & - \\
T3 & Roçada em área total & Roçadeira costal & 75 e 150 dias após a $1^{\text {a }}$ avaliação \\
T4 & Roçada na "entrelinha" & Roçadeira costal & 75 e 150 dias após a $1^{\text {a }}$ avaliação \\
T5 & Roçada - coroamento $1 \mathrm{~m}$ de raio & Roçadeira costal & 75 e 150 dias após a $1^{\text {a }}$ avaliação \\
T6 & Herbicida em área total & Pulverizador costal & 75 e 150 dias após a $1^{\text {a } a v a l i a c ̧ a ̃ o ~}$ \\
T7 & Herbicida na "entrelinha" & Pulverizador costal & 75 e 150 dias após a $1^{\text {a } a v a l i a c ̧ a ̃ o ~}$ \\
T8 & Herbicida - coroamento $1 \mathrm{~m}$ de raio & Pulverizador costal & 75 e 150 dias após a $1^{\text {a avaliação }}$ \\
\hline
\end{tabular}

Fonte: Dados da pesquisa. 
No tratamento T1, as manutenções foram feitas com o objetivo de manter as parcelas do tratamento permanentemente limpas. Nas parcelas do tratamento T2 ou testemunha, não foram realizadas atividades de controle das plantas infestantes, buscando manter as condições naturais de competição e concorrência entre as plantas infestantes e a cultura de interesse.

A motorroçadeira utilizada na realização do controle semimecanizado das plantas infestantes era da marca Stihl ${ }^{\circledR}$, modelo 122, recomendada para uso semiprofissional. A bomba costal que foi utilizada na realização do controle químico das plantas infestantes é da marca Guarani ${ }^{\circledR}$, tanque com capacidade para 20 litros, bico de espuma (Yamaho ${ }^{\circledR}$ ) com aspersão em ângulo de $180^{\circ}$ e um chapéu-de-napoleão para direcionamento da aplicação do produto.

Todos os procedimentos descritos foram realizados com os equipamentos e de acordo com as recomendações da equipe técnica da empresa proprietária das áreas experimentais, rotina normalmente empregada em outras áreas. Dessa forma, nenhum treinamento específico para a implantação dos tratamentos foi realizado.
Cada parcela era composta por seis linhas de plantio (alinhadas no sentido norte-sul) com dez plantas cada, totalizando um número médio de 60 plantas por parcela, das quais foram avaliadas as 40 centrais. Delimitaram-se as parcelas com estacas em seus cantos e todas as estacas possuíam marcações do número do tratamento na parte superior. As alocações foram realizadas com o auxílio de cinco pessoas, três trenas e quatro balizas.

O experimento foi instalado em blocos ao acaso, com quatro repetições, cada bloco abrigando oito parcelas de $400 \mathrm{~m}^{2}$, mais áreas de bordaduras e áreas ocupadas pelas leiras, em um total de 32 parcelas (Quadro 1). A área total utilizada foi de aproximadamente $90.000 \mathrm{~m}^{2}$.

Os blocos foram alocados nos espaços utilizados para o cultivo de eucaliptos, entre as leiras de resíduos da colheita, mantendo sempre uma distância superior a cinco metros das leiras. Os oito tratamentos em estudo foram casualizados nas unidades experimentais, segundo arranjo fatorial 2 (roçada, herbicida) $\times 3$ (área total, entrelinha, coroamento), mais dois tratamentos adicionais (testemunha sem controle, roçadas para controle total).

Quadro 1 - Distribuição e alocação das unidades amostrais

\begin{tabular}{|c|c|c|c|c|c|c|c|c|}
\hline$\uparrow$ Sul & Bordadura & Bordadura & Bordadura & Bordadura & Bordadura & Bordadura & Bordadura & Bordadura \\
\hline Bordadura & T4 & Bordadura & T5 & Bordadura & $\mathrm{T} 1$ & Bordadura & $\mathrm{T} 2$ & Bordadura \\
\hline Bordadura & Bordadura & Bordadura & Bordadura & Bordadura & Bordadura & Bordadura & Bordadura & Bordadura \\
\hline Bordadura & $\mathrm{T} 2$ & Bordadura & $\mathrm{T7}$ & Bordadura & T5 & Bordadura & T8 & Bordadura \\
\hline Bordadura & Bordadura & Bordadura & Bordadura & Bordadura & Bordadura & Bordadura & Bordadura & Bordadura \\
\hline Bordadura & T8 & Bordadura & $\mathrm{T} 1$ & Bordadura & T6 & Bordadura & T3 & Bordadura \\
\hline Bordadura & Bordadura & Bordadura & Bordadura & Bordadura & Bordadura & Bordadura & Bordadura & Bordadura \\
\hline Bordadura & T6 & Bordadura & T3 & Bordadura & T4 & Bordadura & T5 & Bordadura \\
\hline Bordadura & Bordadura & Bordadura & Bordadura & Bordadura & Bordadura & Bordadura & Bordadura & Bordadura \\
\hline Bordadura & T5 & Bordadura & $\mathrm{T} 2$ & Bordadura & T8 & Bordadura & $\mathrm{T7}$ & Bordadura \\
\hline Bordadura & Bordadura & Bordadura & Bordadura & Bordadura & Bordadura & Bordadura & Bordadura & Bordadura \\
\hline Bordadura & $\mathrm{T} 7$ & Bordadura & T8 & Bordadura & $\mathrm{T} 2$ & Bordadura & $\mathrm{T} 1$ & Bordadura \\
\hline Bordadura & Bordadura & Bordadura & Bordadura & Bordadura & Bordadura & Bordadura & Bordadura & Bordadura \\
\hline Bordadura & $\mathrm{T} 1$ & Bordadura & T6 & Bordadura & T5 & Bordadura & T4 & Bordadura \\
\hline Bordadura & Bordadura & Bordadura & Bordadura & Bordadura & Bordadura & Bordadura & Bordadura & Bordadura \\
\hline Bordadura & T3 & Bordadura & T4 & Bordadura & $\mathrm{T7}$ & Bordadura & T6 & Bordadura \\
\hline Bordadura & Bordadura & Bordadura & Bordadura & Bordadura & Bordadura & Bordadura & Bordadura & $\downarrow$ Norte \\
\hline
\end{tabular}


Os dados meteorológicos (temperatura/precipitação) do ano de 2007 foram obtidos no site da Universidade de Joinvile (Univille), os quais são provenientes de sua estação meteorológica, localizada no município de Joinvile, SC.

\section{Coleta das variáveis dependentes}

As variáveis dependentes "diâmetro de colo" e "mortalidade de plantas" de Eucalyptus L’Hér., 1789, foram coletadas aos 10, 100, 190 e 280 dias após o plantio das mudas, isto é, aos 65 dias antes da aplicação dos tratamentos, aos 25 dias após a $1^{\mathrm{a}}$ aplicação dos tratamentos (DAT) e aos 50 e 130 DAT após a 2 ${ }^{\underline{a}}$ aplicação, respectivamente. Os dados foram organizados em tabelas de Excel e posteriormente submetidos à análise de variância, com as médias comparadas pelo teste de Tukey, ao nível de 95\% de probabilidades, com emprego do software MSTAT C e o ASSISTAT 7.5 BETA.

Variável diâmetro de colo

O diâmetro de colo das 40 mudas centrais de cada unidade experimental foi determinado com o auxílio de paquímetros analógicos com precisão de uma casa decimal.

Mortalidade

A quantificação da mortalidade de mudas de Eucalyptus L'Hér., 1789, foi realizada nas mesmas plantas em que foi aferido o diâmetro de colo, mantendo-se o delineamento experimental.

\section{Resultados e discussão}

\section{Crescimento diamétrico}

Nas avaliações do diâmetro de colo das mudas, realizadas em quatro ocasiões, 10, 100, 190 e 280 dias após o plantio, constatou-se o aumento significativo das dimensões dessa variável nas plantas de todas as unidades amostrais quando comparadas às duas últimas avaliações, em relação às duas primeiras.
Na avaliação inicial dessa variável, constatou-se a ausência de diferença estatisticamente significativa entre os blocos e entre os tratamentos. De acordo com Koehler (1999), esse resultado indica que as unidades amostrais são adequadas para a avaliação de efeitos isolados dos diferentes tratamentos silviculturais sugeridos sobre o desenvolvimento diamétrico da cultura em questão.

$\mathrm{Na}$ primeira avaliação, as plantas observadas apresentaram os diâmetros de colo médio de: 2,84 $\mathrm{mm}$ para T1; 2,85 $\mathrm{mm}$ para T2; 2,88 $\mathrm{mm}$ para T3; 2,92 $\mathrm{mm}$ para T4; 2,94 $\mathrm{mm}$ para T5; 2,83 $\mathrm{mm}$ para T6; 2,93 mm para T7; e 2,92 mm para T8.

Na segunda avaliação, as mudas de Eucalyptus L'Hér., 1789, apresentaram as seguintes médias de crescimento em diâmetro de colo: T1 - 16,73 mm; T2 - 16,62 mm; T3 -18,03 mm; T4 - 14,15 mm; T5 $17,16 \mathrm{~mm}$; T6 - 17,31 mm; T7 - 14,72 mm; e T8 $15,32 \mathrm{~mm}$.

0 processamento desses dados demonstrou a existência de diferenças estatisticamente significativas para probabilidade de confiança de 99\% (ANOVA) entre os tratamentos. No teste de comparação de médias de Tukey, para probabilidade de confiança de $95 \%$, os tratamentos T1, T2, T3, T5 e T6 foram declarados estatisticamente iguais, apresentando diferenças significativas em relação aos tratamentos T4, T7 e T8. Contudo, quando T1, T2, T3, T5 e T6 são comparados entre si, formam dois blocos distintos, em que T3, T5 e T6 apresentam diferenças significativas em relação a T1 e T2. No Gráfico 1 é possível observar que os tratamentos nos quais as plantas infestantes foram controladas próximas às plantas da cultura de Eucalyptus L'Hér., 1789, o crescimento diamétrico foi significativamente mais elevado.

Na terceira avaliação (190 dias após a instalação do experimento), as mudas de Eucalyptus L'Hér., 1789, apresentaram as seguintes médias de crescimento em diâmetro de colo: T1 - 31,32 mm; T2 - 29,35 mm; T3 - 31,76 mm; T4 - 25,83 mm; T5 - 30,96 mm; T6 27,84 mm; T7 - 24,57 mm; e T8 -26,04 mm. Ao serem processados, esses dados apresentaram diferenças estatisticamente significativas para probabilidade de confiança de 99\%, de acordo com a ANOVA.

No teste de Tukey para a comparação de médias, com a probabilidade de confiança de $95 \%$, os tratamentos T1, T2, T3, T5 e T6 foram declarados estatisticamente iguais, apresentando diferenças significativas em relação aos tratamentos T4, T7 e T8, 


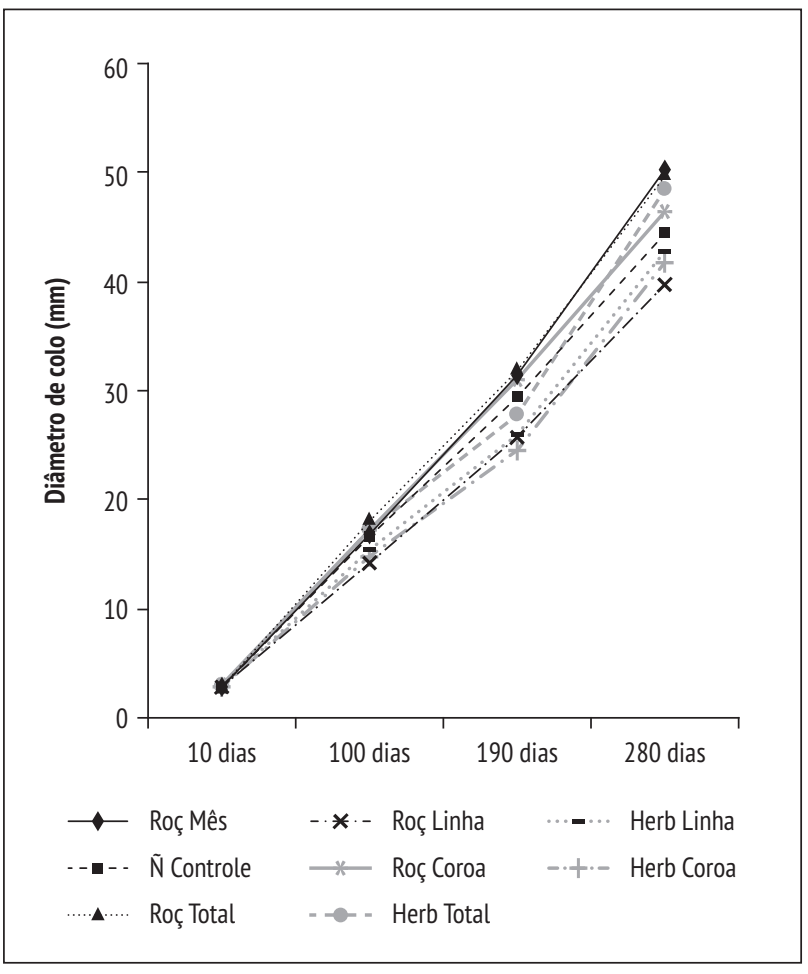

Gráfico 1 - Diâmetro médio de colo dos tratamentos durante o monitoramento

porém, quando T1, T2, T3, T5 e T6 foram comparados entre si, formaram dois blocos distintos e T3, T5 e T6 apresentaram diferenças significativas em relação a T1 e T2, assim como nos resultados observados após a análise dos dados da segunda avaliação.

As mudas de Eucalyptus L'Hér., 1789, na última avaliação, realizada 280 dias após a implantação dos experimentos, apresentaram as seguintes médias de crescimento em diâmetro de colo: 50,31 mm para T1; 44,35 mm para T2; 49,69 mm para T3; 39,67 $\mathrm{mm}$ para $\mathrm{T} 4 ; 46,45 \mathrm{~mm}$ para $\mathrm{T} 5 ; 48,48 \mathrm{~mm}$ para $\mathrm{T} 6$; $41,79 \mathrm{~mm}$ para T7; e $42,76 \mathrm{~mm}$ para T8. Os resultados dessa avaliação evidenciaram diferenças estatísticas significativas entre os diferentes tratamentos, para probabilidade de confiança de $99 \%$, de acordo com a ANOVA.

Ao submeter os dados ao teste de Tukey, constatou-se que os tratamentos T1, T3, T5 e T6 foram declarados estatisticamente iguais entre si e superiores aos demais, com exceção de T5, que é estatisticamente similar a T2 e T8. 0 tratamento T4 apresentou o menor resultado de crescimento diamétrico, porém, esse resultado não difere estatisticamente dos resultados dos tratamentos T7 e T8.
Concluídos os experimentos, os dados obtidos indicam que os tratamentos $\mathrm{T} 1$ (roçada semimecanizada em área total a cada 30 dias), T3 (roçada semimecanizada em área total) e T6 (aplicação de herbicida em área total) apresentaram crescimento diamétrico superior aos demais tratamentos, tendência que foi observada desde a segunda avaliação até o final do experimento, exceto para o tratamento T6, que na terceira avaliação teve uma queda de crescimento, conforme está evidenciado no Gráfico 1.

Os dados aqui obtidos seguem a mesma tendência relatada por Perry et al. (1993) e Cantarelli (2002), os quais observaram em seus experimentos que a competição entre a cultura e as plantas infestantes influencia principalmente o crescimento em diâmetro das culturas florestais. No caso específico deste trabalho, essa observação ficou bem evidenciada no crescimento diamétrico das mudas de Eucalyptus L'Hér., 1789, submetidas aos tratamentos T4 (roçada semimecanizada nas entrelinhas) e T7 (aplicação de herbicida nas entrelinhas), que tiveram as menores médias finais de crescimento diamétrico, em função das características desses tratamentos; as mudas dessas parcelas não tiveram as plantas infestantes controladas nas proximidades das mudas de eucaliptos, afetando diretamente o incremento dos diâmetros.

Contudo, esse comportamento não se manifestou no tratamento T2 (testemunha), no qual as plantas infestantes não sofreram qualquer intervenção após a implantação do experimento. Nas parcelas desse tratamento, a média do crescimento final em diâmetro das mudas de Eucalyptus L'Hér., 1789, não foi a mais alta, porém, esteve no segundo grupo de maior crescimento, sendo esse tratamento estatisticamente igual aos tratamentos T5 e T8 e estatisticamente superior aos tratamentos T4 e T7.

Uma hipótese para o comportamento observado nos tratamentos T2, T4 e T7 talvez seja a competição entre as próprias plantas infestantes. Nos tratamentos T4 e T7, o fato de o controle ter sido exercido nas entrelinhas de plantio pode ter favorecido as plantas infestantes, que permaneceram na linha do plantio. Com o crescimento acentuado destas, as mudas de Eucalyptus L'Hér., 1789, podem ter sido mais afetadas pela competição. Já no tratamento T2, as plantas infetantes competiam com as mudas, porém sofriam maior competição com as plantas que estavam nas entrelinhas. Por isso, podem não ter tido um vigor tão acentuado, prejudicando menos o 
crescimento em diâmetro das mudas de Eucalyptus L'Hér., 1789. Vale ressaltar que tal dedução trata-se de uma hipótese, que precisa de outros experimentos e observações de campo para ser validada.

Os resultados inferiores dos tratamentos submetidos às técnicas de controle químico T7 e T8 são atribuídos à deriva do herbicida durante sua aplicação; esta foi causada por erros operacionais ocorridos por falta de treinamento dos operadores e pela utilização inadequada dos equipamentos utilizados pela prestadora de serviços que executou a implementação dos tratamentos.

\section{Mortalidade das plantas nas áreas experimentais}

Após a implantação do povoamento foi realizado um único replantio, simultâneo à instalação das parcelas (esse replantio não foi quantificado), dez dias após o plantio, em todas as parcelas, com o objetivo de proceder à avaliação em condições similares. Assim, a mortalidade de mudas foi igual a zero na avaliação inicial, sendo constatada somente a partir do trigésimo dia (no segundo levantamento de sobrevivência), realizado 40 dias após o plantio inicial.

Durante a efetuação dos levantamentos de sobrevivência, realizados simultaneamente aos monitoramentos do crescimento, foi possível observar que, até a implementação dos diferentes tratamentos de controle das comunidades infestantes, as taxas de mortalidade entre as unidades amostrais eram estatisticamente homogêneas para uma probabilidade de confiança de $95 \%$. As médias das taxas de mortalidade até a execução da primeira intervenção, nos tratamentos T3, T4, T5, T6, T7 e T8, foram próximas a $2 \%$ para todos os tratamentos, considerando-se que tal fato, sendo inicial, pode ter sido ocasionado por problemas de plantio, entre outros (mortalidade natural).

Contudo, no tratamento com roçadas em área total, com repetições mensais (T1), foi constatada maior taxa de mortalidade em relação aos demais tratamentos com uso de roçadas, o que pode ter ocorrido por erros operacionais na execução das atividades, como o corte das plantas da cultura de interesse, confirmando as citações de Toledo (2002).

Contudo, após a implementação das diferentes técnicas silviculturais de controle das plantas infestantes, observou-se uma elevação nas taxas de mor- talidade nas unidades amostrais, que receberam os tratamentos de controle com o ingrediente ativo glyphosate, pois à medida que as plantas apresentavam sintomas de intoxicação por glyphosate aumentavam as taxas de mortalidade das mudas que receberam tratamentos com esse ingrediente ativo.

Constatou-se a ocorrência de sintomas da aplicação do ingrediente ativo glyphosate, pois diversos sintomas atribuídos a esse produto por Santos et al. (2007), como murcha de ponteiro e clorose das folhas localizadas nas extremidades dos galhos próximos ao solo, foram observados nas plantas dessas unidades amostrais, o que pode ter ocasionando menor desenvolvimento da altura das plantas.

0 último monitoramento de mortalidade foi realizado 290 dias após a implantação do povoamento. Nesse levantamento, as taxas de mortalidade constatadas em alguns tratamentos foram significativamente superiores às aferidas nos demais tratamentos.

No tratamento T6 (controle químico em área total), a taxa de mortalidade média foi de $31,25 \%$, enquanto na testemunha (T2), na qual não foram realizadas intervenções de controle da comunidade infestante, a taxa de mortalidade foi de aproximadamente 3\% (Gráfico 2). Esses dados confirmam a citação de Fontes et al. (2003), os quais comentam que o uso incorreto de herbicidas pode ocasionar a morte das plantas de interesse.

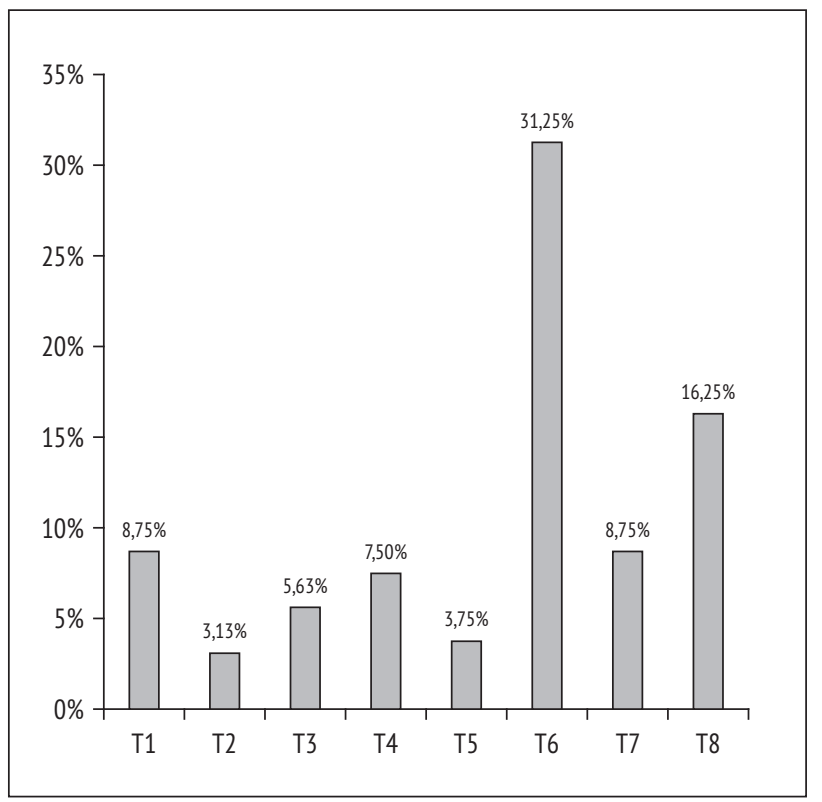

Gráfico 2 - Percentual de mortalidade durante o período de avaliação 
Os dados da comparação entre o tratamento T2 e T6 destacam, mais uma vez, a influência da utilização do herbicida, o que, possivelmente, foi provocado por problemas operacionais e de dimensionamento de equipamentos observados em campo durante a realização das intervenções.

Durante as aplicações foram constatados os seguintes fatos: erros operacionais, como a imprecisão dos operadores (sem treinamento); utilização inadequada de equipamentos e acessórios; equipamentos inadequados, como a utilização de facas de duas pontas em vez de facas de três ou quatro pontas; motores semiprofissionais em vez de profissionais, com maior potência e menor consumo; utilização inadequada de acessórios, como acoplagem errada do chapéu-de-napoleão; falta de válvula de controle de pressão durante a operação da bomba-costal para aplicação de herbicida, entre outros. Constatou-se, durante a realização das manutenções, que os equipamentos eram inadequados à execução das atividades para as quais estavam sendo utilizados.

Os resultados observados durante a implantação das técnicas de controle das plantas infestantes indicam a necessidade da realização de treinamentos aos funcionários e prestadores de serviço, pois medidas simples e eficazes devem ser adotadas durante a execução das atividades de manutenção para obtenção de melhores resultados.

A padronização de ações, como, por exemplo, a supressão parcial de plantas nas entrelinhas de plantio, quando elas estiverem com flores, frutos ou sementes; maior perícia na utilização de equipamentos, como as roçadeiras motorizadas, e no direcionamento do jato durante a aplicação de herbicidas; instalação e montagem adequada dos equipamentos podem contribuir para melhorar o rendimento das atividades de manutenção.

Diante dessas constatações, fica evidente que a padronização e adequação dos equipamentos, de acordo com as necessidades locais, para o controle adequado das plantas infestantes, é de suma importância para o sucesso na execução das atividades de manutenção, assim como os equipamentos utilizados devem atender às exigências ambientais, ergonômicas e econômicas consideradas para a execução das metodologias silviculturais de controle das plantas infestantes, de acordo com as exigências das agências certificadoras.

\section{Conclusões}

Com base nos resultados obtidos neste trabalho, pode-se concluir que:

- o crescimento diamétrico das plantas é favorecido pelo controle semimecanizado de plantas infestantes em área total;

- o crescimento diamétrico sofre reduções consideráveis em razão da competição próxima às plantas da cultura;

- as mudas submetidas a roçadas mensais em área total apresentam maior crescimento para a variável diâmetro de colo.

\section{Referências}

AGROFIT. Sistema de agrotóxicos fitossanitário. Disponível em: <http://agrofit.agricultura.gov.br>. Acesso em: $18 \mathrm{dez} .2008$.

ALVES, P. L. C. A. Estudos das propriedades alalopáticas de espécies de Eucalyptus L'Hér., 1789 e sua potencialidade no manejo de plantas daninhas. Jaboticabal: FCAV, 1992. p. 63. Relatório FINEP.

CANTARELLI, E. B. Efeito de cobertura e períodos de manejo de plantas daninhas no desenvolvimento inicial de Pinus elliotti, Pinus taeda e Pinus elliotti var. elliottii $x$ Pinus caribea var. hondurensis em várzeas. 2002. 86 f. Dissertação (Mestrado em Engenharia Florestal) Universidade Federal de Santa Maria, Santa Maria, 2002.

CHRISTOFFOLETI, P. J. et al. Controle de plantas daninhas em Pinus taeda através do herbicida imazapyr. Piracicaba: Instituto de Pesquisas e Estudos Florestais, 1998. p. 187. Circular Técnica IPEF.

COBUCCI, T.; DI STEFANO, J. G.; KLUTHCOUSKI, J. Manejo de plantas daninhas na cultura do feijoeiro em plantio direto. Santo Antônio de Goiás: Embrapa Arroz e Feijão, 1999.

COX, C. Northeast Coalition for Alternatives to Pesticides. Journal of Pesticide Reform/Fall, Eugene, v. 18, n. 3, 1998. Disponível em: <www.pesticide.org >. Acesso em: 21 jan. 2011.

DEUBER, R. Ciência das plantas infestantes: manejo. Campinas: Edição do Autor, 1997. 
EMPRESA BRASILEIRA DE PESQUISA AGROPECUÁRIA EMBRAPA. Controle de plantas invasoras em pastagens cultivadas nos cerrados. 2008. Disponível em: <www.cnpgc.embrapa.br/publicacoes/doc/doc117/ 05metodos.html>. Acesso em: 20 jul. 2008.

FERREIRA, J. E. F. Herbicidas em florestas. Boletim Informativo do IPEF, Piracicaba, n. 5, p. 262-341, 1977.

FONTES, J. R. A. et al. Lixiviação de herbicidas no solo aplicado com água de irrigação em plantio direto. Planta Daninha, v. 22, p. 623-631, 2003.

KOEHLER, H. S. Estatística experimental. Curitiba: Universidade Federal do Paraná, Departamento de Fitotecnia, 1999.

KREIJCI, L. C.; LOURENO, P. Y. Utilização de herbicidas na área florestal da Copener. Informativo Técnico Copener, Alagoinhas, v. 6, n. 8, p. 92-115, 1987.

LORENZI, H. Plantas daninhas do Brasil. 3. ed. São Paulo: Instituto Plantarum de Estudos da Flora Ltda; Nova Odessa, 2000.

PERRY, M. A. et al. Competitive responses of loblolly pine, sweetgum and broomsedge densities. Canadian Journal Forest Research, v. 23, n. 10, p. 2049-2058, 1993.

PITELLI, R. A. Competição e controle das plantas daninhas em áreas agrícolas. In: SEMINÁRIO TÉCNICO SOBRE HERBICIDAS EM REFLORESTAMENTOS. Piracicaba, 1986. Série Técnica - IPEF, v. 4, n. 12, p. 25-35, 1987.

PITELLI, R. A.; MARCHI, S. R. Interferência das plantas invasoras nas áreas de reflorestamento. In: SEMINÁRIO TÉCNICO DE PLANTAS DANINHAS E O USO DE HERBICIDAS EM REFLORESTAMENTOS, 3., 1991, Belo Horizonte. Anais... Belo Horizonte: Seminário Técnico de Plantas Daninhas e o uso de Herbicidas em Reflorestamentos, 1991. p. 1-11.
PRIMAVESI, A. Manejo ecológico do solo: a agricultura em regiões tropicais. São Paulo: Nobel, 2002.

RODRIGUES, B. N.; ALMEIDA, F. A. Guia de herbicidas. 5. ed. Londrina: Edição dos Autores, 2005.

SANTOS, L. D. T. et al. Crescimento e concentração de nutrientes na parte aérea de eucaliptos sob o efeito da deriva do glyphosate. Revista CERNE, Lavras, v. 13, n. 4. p. 347352, 2007.

TOLEDO, R. E. B. Efeitos da faixa de controle e dos períodos de controle e de convivência de Brachiaria decumbens Stapf no desenvolvimento inicial de plantas de Eucalyptus urograndis. 1998. 71 f. Dissertação (Mestrado em Engenharia Florestal) - Escola Superior de Agricultura “Luiz de Queiroz", Universidade de São Paulo, Piracicaba, 1998.

TOLEDO, R. E. B. et al. Comparação dos custos de quatro métodos de manejo de Brachiaria decumbens Staf em área de implantação de Eucalyptus grandis W. Hill ex Maiden. Revista Árvore, Viçosa, v. 20, n. 3, p. 319-330, 1996.

TOLEDO, R. E. B. Faixas e períodos de controle de plantas daninhas e seus reflexos no crescimento do eucalipto. 2002. 130 f. Tese (Doutorado em Engenharia Florestal) - Escola Superior de Agricultura "Luiz de Queiroz", Universidade de São Paulo, Piracicaba, 2002.

WIKLER, C. Projeto Tibouchina. Curitiba: UFPR, 2000. (Relatório técnico).

Recebido: 15/03/2011

Received: 03/15/2011

Aprovado: 05/04/2011

Approved: 04/05/2011 